\title{
The Functional Divide for Primary Reinforcement of D- Amphetamine Lies between the Medial and Lateral Ventral Striatum: Is the Division of the Accumbens Core, Shell, and Olfactory Tubercle Valid?
}

\author{
Satoshi Ikemoto, Mei Qin, and Zhong-Hua Liu \\ Behavioral Neuroscience Branch, National Institute on Drug Abuse, National Institutes of Health, Department of Health and Human Services, Baltimore, \\ Maryland 21224
}

\begin{abstract}
When projection analyses placed the nucleus accumbens and olfactory tubercle in the striatal system, functional links between these sites began to emerge. The accumbens has been implicated in the rewarding effects of psychomotor stimulants, whereas recent work suggests that the medial accumbens shell and medial olfactory tubercle mediate the rewarding effects of cocaine. Interestingly, anatomical evidence suggests that medial portions of the shell and tubercle receive afferents from common zones in a number of regions. Here, we report results suggesting that the current division of the ventral striatum into the accumbens core and shell and the olfactory tubercle does not reflect the functional organization for amphetamine reward. Rats quickly learned to self-administer D-amphetamine into the medial shell or medial tubercle, whereas they failed to learn to do so into the accumbens core, ventral shell, or lateral tubercle. Our results suggest that primary reinforcement of amphetamine is mediated via the medial portion of the ventral striatum. Thus, the medial shell and medial tubercle are more functionally related than the medial and ventral shell or the medial and lateral tubercle. The current core-shelltubercle scheme should be reconsidered in light of recent anatomical data and these functional findings.
\end{abstract}

Key words: reward; intracranial self-administration; psychomotor stimulants; nucleus accumbens; olfactory tubercle; reinforcing

\section{Introduction}

Brain regions are distinguished and named to identify each region with unique functions. The concept of the ventral striatum emerged when Heimer and Wilson (1975) suggested that the olfactory tubercle is part of the striatal system and that the well established isocortico-dorsal striatopallidal system has a parallel system consisting of limbic (piriform, hippocampal, and amygdaloid) cortices projecting to the olfactory tubercle and nucleus accumbens, which, in turn, project to the ventral pallidum.

The nucleus accumbens, which receives dense dopaminergic projections, plays a key role in motivation and primary reinforcement of psychomotor stimulants (Ikemoto and Panksepp, 1999). Rats learn to self-administer D-amphetamine (Hoebel et al., 1983; Phillips et al., 1994), a dopamine releaser and uptake blocker, and other dopaminergic agents directly into the accumbens. The accumbens can be divided into the core and shell, a distinction that originates from the discovery of differential histochemical profile within the accumbens (Zaborszky et al., 1985). There is now ample evidence for functional heterogeneity between the two

Received March 7, 2005; revised April 15, 2005; accepted April 16, 2005.

This work was supported by the National Institute on Drug Abuse Intramural Research Program. We thank David Horton and lan Macumber for technical assistance and Emily Wentzell for editorial assistance.

Correspondence should be addressed to Satoshi lkemoto, Behavioral Neuroscience Branch, National Institute on Drug Abuse, 5500 Nathan Shock Drive, Baltimore, MD 21224. E-mail: sikemoto@intra.nida.nih.gov.

DOI:10.1523/JNEUROSCI.0892-05.2005

Copyright $\odot 2005$ Society for Neuroscience $\quad$ 0270-6474/05/255061-05\$15.00/0 zones (Di Chiara, 2002; Kelley, 2004). With respect to primary drug reinforcement, it has been shown that rats learn to selfadminister the dopamine uptake inhibitors nomifensine (Carlezon et al., 1995) and cocaine (Rodd-Henricks et al., 2002; Ikemoto, 2003) and mixtures of $\mathrm{D}_{1}$ and $\mathrm{D}_{2}$ receptor agonists (Ikemoto et al., 1997) into the shell but not the core. In addition, systemic D-amphetamine-induced conditioned place preference, a measure of reward, can be attenuated by selective lesions of dopaminergic terminals in the shell but not the core (Sellings and Clarke, 2003). However, the evidence used to support functional differences between the core and the shell is applicable only to the medial shell, because most investigators working on this issue compared the core with the medial portion, while ignoring the ventral shell. The crescent-shaped shell lies just medial and ventral to the core, and it is difficult to manipulate the entire shell with a single application of drugs or toxins.

Like the accumbens, the olfactory tubercle receives dense dopaminergic projections from the midbrain. Although it has not received much research attention, the tubercle appears to mediate primary reinforcement of cocaine (Ikemoto, 2003), a process that was widely believed to be mediated by the accumbens. Rats quickly learn to self-administer cocaine into the tubercle. Importantly, the medial tubercle is more responsible than the lateral tubercle for triggering the reinforcing effects of cocaine.

The patterns of the effects of cocaine at various striatal regions do not fit with the currently extant core-shell-tubercle scheme 
but instead support mediolateral functional divisions in the ventral striatum. Indeed, anatomical evidence supports such hypotheses and suggests that the medial shell and medial tubercle receive inputs from common zones in a number of regions, whereas there are significant differences in afferents between the medial and ventral shell and between the medial and lateral tubercle (see Discussion below for detailed information). To examine these functional divisions, we sought for additional behavioral evidence and studied different effects of D-amphetamine within the ventral striatum using intracranial self-administration procedures.

\section{Materials and Methods}

Animals. Male Wistar rats (270-350 g at the time of surgery; Harlan, Dublin, VA) were used. Food and water were available ad libitum except during testing. The procedures were approved by the Animal Care and Use Committee of the National Institute on Drug Abuse Intramural Research Program and were in accordance with National Institutes of Health guidelines.

Surgery. Rats were stereotaxically implanted with permanent unilateral guide cannulas (24 gauge) under sodium pentobarbital $(31 \mathrm{mg} / \mathrm{kg}$, i.p.) and chloral hydrate $(142 \mathrm{mg} / \mathrm{kg}$, i.p.) anesthesia. Each rat's guide cannula ended $1.0 \mathrm{~mm}$ above one of five target regions. Because efflux from central injections tends to follow a pressure gradient up the cannula shaft (Routtenberg, 1972), the cannulas for medial shell and medial tubercle sites were inserted at a $20^{\circ}$ angle from the other hemisphere through the midline (see Fig. $1 A$ ) to minimize diffusion of drug solution to the core or shell, respectively. The cannulas were inserted vertically for injections in the core, ventral shell, and lateral tubercle. The incisor bar was set at $3.3 \mathrm{~mm}$ below the interaural line. The stereotaxic coordinates were $2.0 \mathrm{~mm}$ anterior to bregma (A), $2.0 \mathrm{~mm}$ lateral to the midline (L), and $8.2 \mathrm{~mm}$ ventral to the skull surface $(\mathrm{V})$ (measured along the trajectory of the angled cannula) for medial tubercle placements; A2.0, L1.6, and V7.2 for medial shell placements; A2.0, L2.5, and V8.4 for lateral tubercle placements; A2.0, L2.3, and V7.7 for ventral shell placements; and A2.0, L1.9, and V6.6 for core placements.

Drugs. D-Amphetamine (Sigma, St. Louis, MO) was dissolved in an artificial CSF consisting of the following (in $\mathrm{mM}$ ): $148 \mathrm{NaCl}, 2.7 \mathrm{KCl}, 1.2$ $\mathrm{CaCl}_{2}$, and $0.85 \mathrm{MgCl}_{2}, \mathrm{pH}$ adjusted to $6.8-7.7$.

Regional amphetamine effect experiment. The first six sessions were designed to examine the acquisition of self-administration, whereas the last four sessions determined the effects of amphetamine concentrations on self-administration as a function of injection regions. To determine the effectiveness of amphetamine reinforcement in each region, 48 rats with no previous operant training were placed the operant chambers $(30 \times 22 \times 24 \mathrm{~cm})$ equipped with a lever $(45 \mathrm{~mm}$ wide $\times 2 \mathrm{~mm}$ thick, protruding $20 \mathrm{~mm}$ from the wall) below a cue light. Each rat's 31 gauge injection cannula was connected by polyethylene tubing to a micropump (Ikemoto and Sharpe, 2001) hanging a few millimeters above the rat's head. A lever press extinguished the cue light for $5 \mathrm{~s}$ and turned on the micropump for $5 \mathrm{~s}$, dispensing a $75 \mathrm{nl}$ infusion; additional lever presses were not rewarded until another $5 \mathrm{~s}$ passed, at which time the cue light was reinstated. We chose the following concentrations of amphetamine, considering previous studies on intraaccumbens injections of amphetamine (Hoebel et al., 1983; Phillips et al., 1994; Ikemoto, 2002). Rats received $30 \mathrm{~mm}$ amphetamine in sessions 2 and 3, $100 \mathrm{~mm}$ in sessions 4 and 5 , and vehicle in sessions 1 and 6 (acquisition phase), followed by 10 , 30 , and $100 \mathrm{~mm}$ over three sessions in this order (concentration-response relationship test). The maximum number of infusions available per session was limited to 60 to minimize the possibility of tissue damage. Sessions lasted $90 \mathrm{~min}$ or until the rats received a total of 60 infusions.

Two-lever discrimination experiment. To examine the specificity of behavioral effects of amphetamine administered into the medial tubercle, six rats with no previous operant training were placed in operant chambers identical to those described above, except that they had two retractable levers. A response on the "active" lever resulted in a $5 \mathrm{~s}$ infusion (75 $\mathrm{nl}$ in volume), extinguished a cue light above the lever, and retracted both levers for $30 \mathrm{~s}$. A response on the "inactive" lever did not deliver infusions but retracted both the active and inactive levers for $30 \mathrm{~s}$. The light above the inactive lever was never turned on. The left lever was designated as the active lever for three rats and as the inactive lever for the other three. Responding on the active lever produced vehicle infusions in session 1 and $100 \mathrm{~mm}$ amphetamine infusions in sessions 2-4. Sessions lasted 90 min or until the rats received a total of 60 infusions. Numbers of responses on each lever were recorded.

Histology. When each rat completed the experimental procedure, the rat was anesthetized with sodium pentobarbital $(31 \mathrm{mg} / \mathrm{kg}$, i.p. $)$ and chloral hydrate ( $142 \mathrm{mg} / \mathrm{kg}$, i.p.), and its brain was removed and placed in a $4 \%$ paraformaldehyde solution. Within 1 week, the brain was cut with a cryostat in coronal $40 \mu \mathrm{m}$ sections, and the placement of the cannula was confirmed with microscopic examination. Rats with cannula placements outside of target regions were excluded from behavioral analyses.

Statistical analyses. Rates of infusions during the acquisition phase were analyzed with three-by-two within-subjects ANOVAs with concentration (vehicle, $30 \mathrm{~mm}$, and $100 \mathrm{~mm}$ ) and trial (two) as factors, performed for five regions separately, followed by Newman-Keuls post hoc tests. Rates of infusions for the last four sessions were analyzed with a five-by-four mixed ANOVA with two factors: region (the five regions; between-subjects factor) and concentration $(0,10,30$, and $100 \mathrm{~mm}$ amphetamine; within-subject factor). Significant main region effect was further analyzed with Newman-Keuls post hoc tests. Significant interaction effect between region and concentration was further analyzed with Dunnett's post hoc tests, which allowed us to focus on comparisons of concentration effects for each region separately and to avoid all possible comparisons.

For the two-lever discrimination experiment, the numbers of leverpresses were analyzed with a two-by-four within-subjects ANOVA with lever (active and inactive) and session (1-4) as factors, followed by Newman-Keuls post hoc tests.

\section{Results}

Locations of injection cannulas for the five regions are shown in Figure 1, $B$ and $C$. Amphetamine was self-administered at significantly higher rates into the medial tubercle $\left({ }^{* *} p<0.001\right)$ or medial shell $\left({ }^{*} p<0.05\right)$ than into the lateral tubercle, ventral shell, or core (a significant region effect; $F_{(4,43)}=7.84 ; p<$ 0.0001 ) (Fig. $1 D$ ). In addition, there was an insignificant trend that rats self-administered amphetamine into the medial tubercle at higher rates than into the medial shell. Medial tubercle rats and medial shell rats self-administered 10,30 , and $100 \mathrm{~mm}$ amphetamine significantly more than vehicle, whereas the rats in other groups did not self-administer amphetamine more than vehicle (after a significant region-by-concentration interaction effect; $\left.F_{(12,129)}=4.11 ; p<0.0001\right)$. Similar results were found in the analysis for the acquisition of self-administration (during sessions 1-6). Rats quickly learned to self-administer amphetamine into the medial tubercle or the medial shell (main concentration effects; $F_{(2,14)}=8.05, p<0.005$ and $F_{(2,18)}=6.79, p<0.01$, respectively) but not into the lateral tubercle, ventral shell, or core.

Because the role of the tubercle in reinforcement has not yet been established, it is important to address the alternative interpretation that amphetamine administration into the medial tubercle was not reinforcing but merely arousing. Effects of amphetamine in the tubercle were further studied with a two-lever discrimination procedure. A separate group of rats $(n=7)$ was trained to discriminate an active lever from an inactive lever for intramedial tubercle infusions of amphetamine. As shown in Figure $1 E$, rats learned to discriminate between the two levers and responded on the active lever more than the inactive lever in sessions 3 and 4 ( ${ }^{*} p<0.05$; after a significant lever-by-session interaction; $\left.F_{(3,18)}=4.49 ; p<0.05\right)$. 

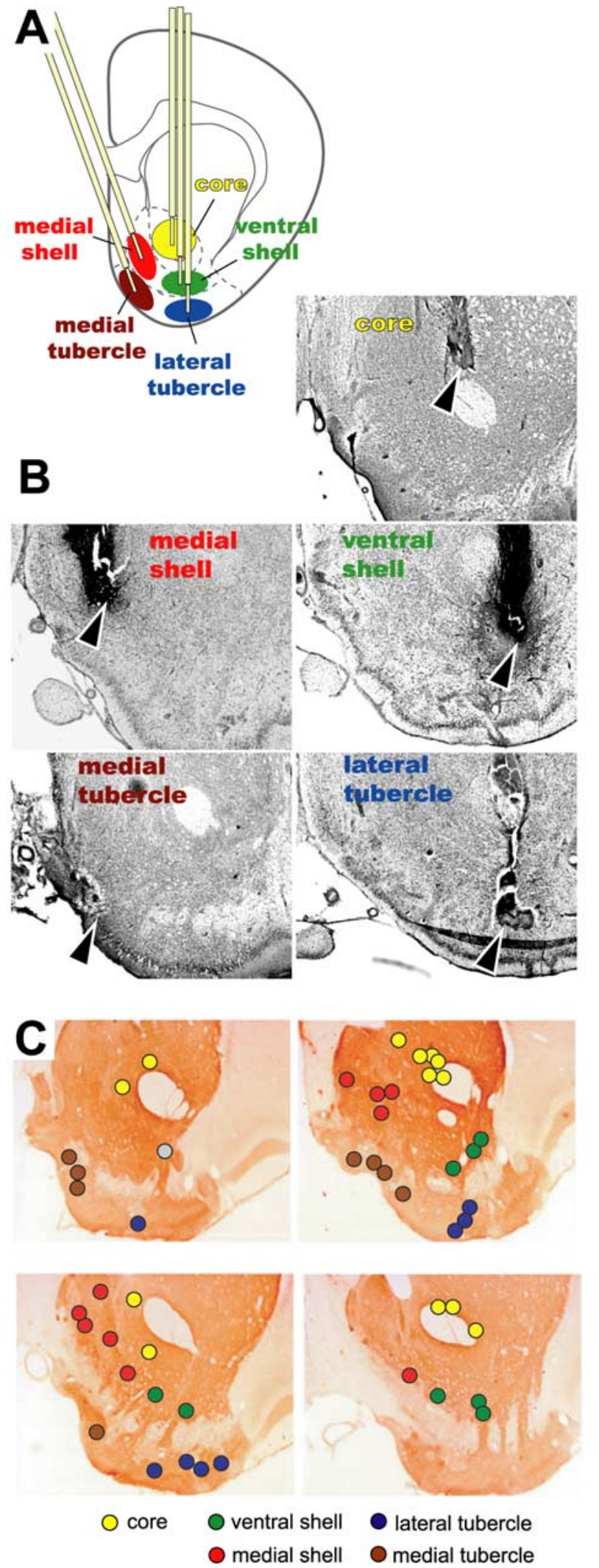

D
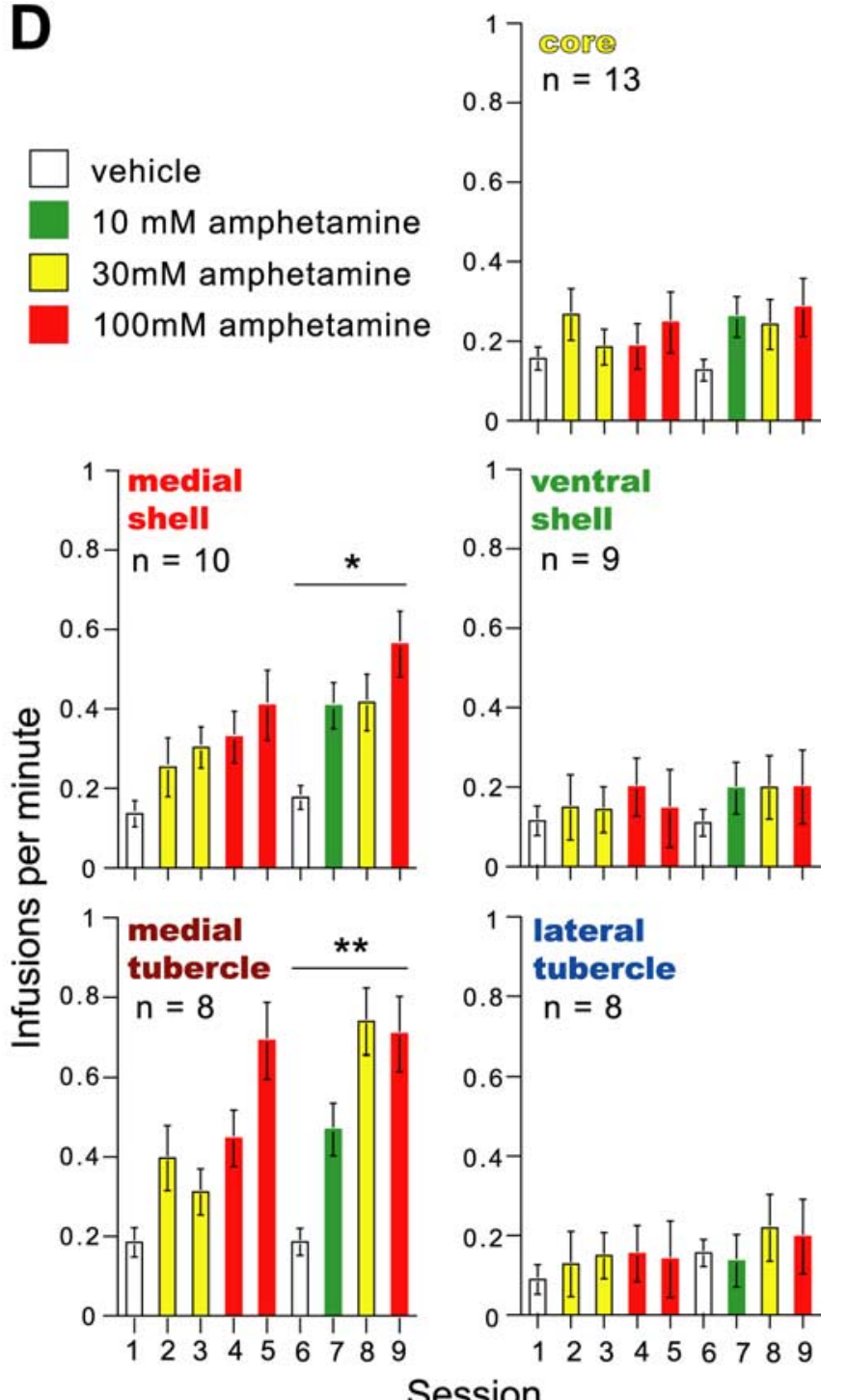

Session

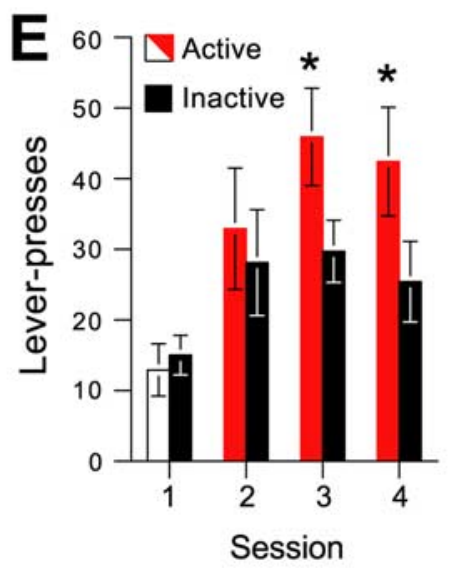

Figure 1. Intracranial self-administration of amphetamine into ventral striatal regions. $\boldsymbol{A}$, Unilateral guide cannulas aimed at the medial tubercle and medial shell were inserted at a $20^{\circ}$ angle from the other hemisphere through the midline, to minimize diffusion of drug solution into the shell or core, respectively. $\boldsymbol{B}$, Photomicrographs show representative placements of cannulas. Arrowheads indicate the tips of injection cannulas. C, The tips of injection cannulas are plotted for each region on tyrosine hydroxylase-stained sections from top left, the most anterior, to bottom right, the most posterior. $D$, Mean \pm SEM rates of self-administration per session as a function of region are shown. The color of each bar indicates the treatment that the rats received for the session. ${ }^{*} p<0.05$ and ${ }^{* *} p<0.001$, significant differences compared with corresponding sessions for the core, ventral shell, and lateral tubercle. $\boldsymbol{E}$, Mean \pm SEM lever presses per session over four consecutive sessions are shown. A response on the active lever resulted in a $75 \mathrm{nl}$ infusion, whereas a response on the inactive lever did not deliver an infusion. Rats received vehicle in session 1 and $100 \mathrm{~mm}$ amphetamine in sessions $2-4 .{ }^{*} p<0.05$, significant difference compared with respective inactive lever presses. 


\section{Discussion}

The findings that rats self-administered amphetamine into the medial shell and medial tubercle but not the core, ventral shell, or lateral tubercle support our hypothesis that the medial ventral striatum (i.e., the medial shell and medial tubercle) is more responsible for the reinforcing effects of amphetamine than the lateral ventral striatum (i.e., the core, ventral shell, lateral tubercle). This hypothesis is consistent with recent data on afferents to the ventral striatum. Although functional evidence has been offered to support the core-shell scheme (Di Chiara, 2002; Kelley, 2004) since the demonstration of anatomical differences between the accumbens core and shell (Zahm and Brog, 1992), the similarities in afferents between the medial shell and medial tubercle and differences between the medial and ventral shell (Groenewegen et al., 1999) and between the medial and lateral tubercle (Newman and Winans, 1980) have not been emphasized. Reviews of recent data on afferents to the ventral striatum in rodents suggest that the medial shell and medial tubercle receive inputs from common zones in a number of regions, whereas there are significant differences in afferents between the medial and ventral shell and between the medial and lateral tubercle [Ikemoto (2002), their Table 1; Voorn et al., 2004]; similar afferent patterns also exist in primates (Haber, 2003).

Dopaminergic inputs to the medial shell and medial tubercle primarily come from the posteromedial ventral tegmental area (VTA) and the central linear nucleus of raphé, whereas inputs to the ventral shell, lateral tubercle, and accumbens core come primarily from the lateral VTA (S. Ikemoto, unpublished observation). Indeed, mediolateral topographic patterns of projections to the accumbens (Fallon and Moore, 1978; Nauta et al., 1978; Beckstead et al., 1979; Phillipson and Griffiths, 1985; Brog et al., 1993 ) and to the tubercle (Newman and Winans, 1980) from the VTA have been characterized. Other major afferents to the ventral striatum are primarily glutamatergic and play a critical role in determining the actions of dopamine. The medial shell and medial tubercle receive inputs from the infralimbic cortex (Berendse et al., 1992), the posterior basolateral amygdaloid nucleus (Krettek and Price, 1978; Russchen and Price, 1984), the ventral subiculum of the hippocampal formation (Kelley and Domesick, 1982; Groenewegen et al., 1987), and the paraventricular thalamic nucleus (Newman and Winans, 1980; Berendse and Groenewegen, 1990; Moga et al., 1995). On the other hand, the afferent sources to ventral shell and lateral tubercle include the ventral agranular insular area (Berendse et al., 1992), the anterior basolateral amygdala (Krettek and Price, 1978; Russchen and Price, 1984), and the parataenial nucleus (Newman and Winans, 1980; Berendse and Groenewegen, 1990; Moga et al., 1995). The fact that the medial shell and medial tubercle receive inputs from common zones suggests that they engage in related functions; however, on the other hand, the fact that distinct zones project between the medial and ventral shell and between the medial and lateral tubercle suggests that significant functional differences exist between them.

Although these anatomical observations support our behavioral findings, we must address a concern about interpreting microinjection studies before using these findings as evidence. Microinjected drugs do not necessarily act at the site of delivery but diffuse to neighboring regions for action; for instance, amphetamine administration into the tubercle could diffuse to the accumbens shell. To address the issue of possible drug diffusion along the cannula track, we implanted cannulas for the medial tubercle at a lateral angle to avoid the shell. In addition, we ex- amined different concentrations of amphetamine over multiple sessions in the medial shell as well as surrounding regions. Drug concentration and rapidity of drug action decrease markedly as the drug diffuses from one site to another. Thus, if the reinforcing effect of amphetamine delivered into the medial tubercle was caused by diffusion to the medial shell, we would expect to see rewarding effects of amphetamine delivered into the core or lateral shell, which are as close to the medial shell as the medial tubercle. Furthermore, rats receiving infusions into the medal shell would respond to amphetamine at lower concentrations and learn to self-administer amphetamine faster than tubercle rats. We did not observe such effects. Instead, the core and ventral shell rats failed to learn to self-administer amphetamine, and the medial tubercle rats tended to self-administer amphetamine more vigorously than the medial shell rats. These observations are consistent with the previous findings that medial tubercle rats self-administer cocaine at lower concentrations than medial shell rats (Ikemoto, 2003), and core rats do not learn to self-administer cocaine. Therefore, it is most likely that the administration of amphetamine into the medial tubercle is reinforcing on its own right.

The process that amphetamine triggers via the medial tubercle and medial shell may be characterized as concerted motivational process rather than "pure" reinforcement. Although rats learned to discriminate between the active and inactive levers, they continued responding on the inactive lever. These high inactive responses in part indicate an arousing effect of amphetamine and are consistent with the heightened locomotion and rearing induced by microinjections of amphetamine into the medial tubercle (Ikemoto, 2002). Colocalization of arousal and reinforcement has been found in other brain regions including the ventral tegmental area, in which carbachol or endomorphin-1 administration triggers both effects (Ikemoto and Wise, 2002; Zangen et al., 2002; Ikemoto et al., 2003), and the supramammillary nucleus, in which AMPA or picrotoxin administration triggers both (Ikemoto et al., 2004; Ikemoto, 2005). We suspect that drug administration into these regions, including the medial tubercle and medial shell, triggers a coordinated set of changes in mental and bodily states involved in the reward-seeking function (Ikemoto and Panksepp, 1999), leading to hyperactivity and reinforcement. We should add that although the regions that are known to trigger primary drug reinforcement appear to always trigger hyperactivity in rats, anatomical substrates of hyperactivity are not always colocalized with those of reinforcement. The accumbens core, for example, which did not readily trigger primary drug reinforcement, plays an important role in triggering locomotor effects of amphetamine (Ikemoto, 2002; Sellings and Clarke, 2003).

The present study contributes to the existing literature in three ways. First, we provide new information that amphetamine is reinforcing when administered into the medial shell and medial tubercle but not the core, ventral shell, or lateral tubercle. In addition, the results suggest that the ventral shell, which has been neglected for functional investigation, does not mediate reinforcement in the same way that the medial shell does. The present results also provide much needed complements to the cocaine study findings that the accumbens core and the lateral tubercle do not mediate reinforcement in the same way as the medial shell and medial tubercle (Carlezon et al., 1995; Rodd-Henricks et al., 2002; Ikemoto, 2003). It is difficult to interpret the absence of reinforcing effects of cocaine because of its local anesthetic action and regional differences in sensitivity to local anesthesia. In addition to monoamine uptake inhibition, cocaine potently inhib- 
its voltage-gated $\mathrm{Na}^{+}$channels, which causes local anesthesia (Catterall and Mackie, 1996). Indeed, at the concentrations that cocaine exerts its motor-stimulant and reinforcing effects when injected into the medial tubercle, it induces local anesthesia and motor depression when injected into the accumbens core (Ikemoto and Witkin, 2003). D-Amphetamine, on the other hand, does not inhibit sodium channels when delivered at the concentrations at which amphetamine stimulates dopamine release and inhibits dopamine uptake. Indeed, the core is as responsible for the motor-stimulant effects of D-amphetamine as the medial shell or medial tubercle (Ikemoto, 2002). The present findings, together with the anatomical data, suggest that the medial shell and medial tubercle are more functionally related than the medial and ventral shell or the medial and lateral tubercle. Additional information, such as data on fine efferent projections, would be helpful in determining whether the medial shell and medial tubercle indeed form a functional unit. In any case, the core-shell-tubercle scheme should be reconsidered in light of recent anatomical data and these functional findings.

\section{References}

Beckstead RM, Domesick VB, Nauta WJ (1979) Efferent connections of the substantia nigra and ventral tegmental area in the rat. Brain Res 175:191-217.

Berendse HW, Groenewegen HJ (1990) Organization of the thalamostriatal projections in the rat, with special emphasis on the ventral striatum. J Comp Neurol 299:187-228.

Berendse HW, Galis-de Graaf Y, Groenewegen HJ (1992) Topographical organization and relationship with ventral striatal compartments of prefrontal corticostriatal projections in the rat. J Comp Neurol 316:314-347.

Brog JS, Salyapongse A, Deutch AY, Zahm DS (1993) The patterns of afferent innervation of the core and shell in the "accumbens" part of the rat ventral striatum: immunohistochemical detection of retrogradely transported fluoro-gold. J Comp Neurol 338:255-278.

Carlezon Jr WA, Devine DP, Wise RA (1995) Habit-forming actions of nomifensine in nucleus accumbens. Psychopharmacology 122:194-197.

Catterall W, Mackie K (1996) Local anesthetics. In: Goodman and Gilman's the pharmacological basis of therapeutics, Ed 9 (Hardman JG, Limbird LE, eds), pp 331-347. New York: McGraw.

Di Chiara G (2002) Nucleus accumbens shell and core dopamine: differential role in behavior and addiction. Behav Brain Res 137:75-114.

Fallon JH, Moore RY (1978) Catecholamine innervation of the basal forebrain. IV. Topography of the dopamine projection to the basal forebrain and neostriatum. J Comp Neurol 180:545-580.

Groenewegen HJ, Vermeulen-Van der Zee E, te Kortschot A, Witter MP (1987) Organization of the projections from the subiculum to the ventral striatum in the rat. A study using anterograde transport of Phaseolus vulgaris leucoagglutinin. Neuroscience 23:103-120.

Groenewegen HJ, Wright CI, Beijer AV, Voorn P (1999) Convergence and segregation of ventral striatal inputs and outputs. Ann NY Acad Sci 877:49-63.

Haber SN (2003) The primate basal ganglia: parallel and integrative networks. J Chem Neuroanat 26:317-330.

Heimer L, Wilson RD (1975) The subcortical projections of the allocortex: similarities in the neural associations of the hippocampus, the piriform cortex, and the neocortex. In: Golgi centenial symposium proceedings (Santini M, ed), pp 177-193. New York: Raven.

Hoebel BG, Monaco AP, Hernandez L, Aulisi EF, Stanley BG, Lenard L (1983) Self-infusion of amphetamine directly into the brain. Psychopharmacology 81:158-163.

Ikemoto S (2002) Ventral striatal anatomy of locomotor activity induced by cocaine, D-amphetamine, dopamine and D1/D2 agonists. Neuroscience 113:939-955.

Ikemoto S (2003) Involvement of the olfactory tubercle in cocaine reward: intracranial self-administration studies. J Neurosci 23:9305-9311.

Ikemoto S (2005) The supramammillary nucleus mediates primary reinforcement via GABA(A) receptors. Neuropsychopharmacology, in press.
Ikemoto S, Panksepp J (1999) The role of nucleus accumbens dopamine in motivated behavior: a unifying interpretation with special reference to reward-seeking. Brain Res Brain Res Rev 31:6-41.

Ikemoto S, Sharpe LG (2001) A head-attachable device for injecting nanoliter volumes of drug solutions into brain sites of freely moving rats. J Neurosci Methods 110:135-140.

Ikemoto S, Wise RA (2002) Rewarding effects of the cholinergic agents carbachol and neostigmine in the posterior ventral tegmental area. J Neurosci 22:9895-9904.

Ikemoto S, Witkin BM (2003) Locomotor inhibition induced by procaine injections into the nucleus accumbens core, but not the medial ventral striatum: implication for cocaine-induced locomotion. Synapse 47:117-122.

Ikemoto S, Glazier BS, Murphy JM, McBride WJ (1997) Role of $D_{1}$ and $D_{2}$ receptors in the nucleus accumbens in mediating reward. J Neurosci 17:8580-8587.

Ikemoto S, Witkin BM, Morales M (2003) Rewarding injections of the cholinergic agonist carbachol into the ventral tegmental area induce locomotion and c-Fos expression in the retrosplenial area and supramammillary nucleus. Brain Res 969:78-87.

Ikemoto S, Witkin BM, Zangen A, Wise RA (2004) Rewarding effects of AMPA administration into the supramammillary or posterior hypothalamic nuclei but not the ventral tegmental area. J Neurosci 24:5758-5765.

Kelley AE (2004) Ventral striatal control of appetitive motivation: role in ingestive behavior and reward-related learning. Neurosci Biobehav Rev 27:765-776.

Kelley AE, Domesick VB (1982) The distribution of the projection from the hippocampus formation to the nucleus accumbens in the rat: an anterograde- and retrograde-horseradish peroxidase study. Neuroscience 7:2321-2335.

Krettek JE, Price JL (1978) Amygdaloid projections to subcortical structures within the basal forebrain and brainstem in the rat and cat. J Comp Neurol 178:225-254.

Moga MM, Weis RP, Moore RY (1995) Efferent projections of the paraventricular thalamic nucleus in the rat. J Comp Neurol 359:221-238.

Nauta WJH, Smith GP, Faul RLM, Domesick VB (1978) Efferent connections and nigral afferent of the nucleus accumbens septi in the rat. Neuroscience 3:385-401.

Newman R, Winans SS (1980) An experimental study of the ventral striatum of the golden hamster. II. Neuronal connections of the olfactory tubercle. J Comp Neurol 191:193-212.

Phillips GD, Robbins TW, Everitt BJ (1994) Bilateral intra-accumbens selfadministration of $\mathrm{D}$-amphetamine: antagonism with intra-accumbens SCH-23390 and sulpiride. Psychopharmacology 114:477-485.

Phillipson OT, Griffiths AC (1985) The topographic order of inputs to nucleus accumbens in the rat. Neuroscience 16:275-296.

Rodd-Henricks ZA, McKinzie DL, Li TK, Murphy JM, McBride WJ (2002) Cocaine is self-administered into the shell but not the core of the nucleus accumbens of Wistar rats. J Pharmacol Exp Ther 303:1216-1226.

Routtenberg A (1972) Intracranial chemical injection and behavior: a critical review. Behav Biol 7:601-641.

Russchen FT, Price JL (1984) Amygdalostriatal projections in the rat. Topographical organization and fiber morphology shown using the lectin PHA-L as an anterograde tracer. Neurosci Lett 47:15-22.

Sellings LH, Clarke PB (2003) Segregation of amphetamine reward and locomotor stimulation between nucleus accumbens medial shell and core. J Neurosci 23:6295-6303.

Voorn P, Vanderschuren LJ, Groenewegen HJ, Robbins TW, Pennartz CM (2004) Putting a spin on the dorsal-ventral divide of the striatum. Trends Neurosci 27:468-474.

Zaborszky L, Alheid GF, Beinfeld MC, Eiden LE, Heimer L, Palkovits M (1985) Cholecystokinin innervation of the ventral striatum: a morphological and radioimmunological study. Neuroscience 14:427-453.

Zahm DS, Brog JS (1992) On the significance of subterritories in the "accumbens" part of the rat ventral striatum. Neuroscience 50:751-767.

Zangen A, Ikemoto S, Zadina JE, Wise RA (2002) Rewarding and psychomotor stimulant effects of endomorphin-1: anteroposterior differences within the ventral tegmental area and lack of effect in nucleus accumbens. J Neurosci 22:7225-7233. 